\title{
IGF1R Immunohistochemical Expression
}

National Cancer Institute

\section{Source}

National Cancer Institute. IGF1R Immunohistochemical Expression. NCI Thesaurus. Code C84373.

An immunohistochemical diagnostic test utilizing an antibody to detect IGF1R in tissues. 